\title{
Factors affecting health care workers' adoption of a website with infection control guidelines
}

\author{
Fenne Verhoeven ${ }^{a, *}$, Michaël F. Steehouder ${ }^{a}$, Ron M.G. Hendrix ${ }^{b}$, \\ Julia E.W.C. van Gemert-Pijnen ${ }^{a}$ \\ a University of Twente, Faculty of Behavioral Sciences, Department of Technical and Professional Communication, \\ PO Box 217, 7500 AE Enschede, The Netherlands \\ b Laboratory for Clinical Microbiology, PO Box 377, 7500 AJ Enschede, The Netherlands
}

\section{A R T I C L E I N F O}

\section{Article history:}

Received 9 February 2009

Received in revised form 6 June 2009

Accepted 7 June 2009

\section{Keywords:}

Practice guideline

Communicable diseases

Qualitative evaluation

Innovation diffusion

\begin{abstract}
A B S T R A C T
Goal: To identify factors that could affect health care workers' (HCWs) adoption of a website for communicating infection control guidelines.

Methods: In total, 20 semi-structured interviews were conducted with HCWs in 5 different occupational groups and 4 different hospitals in the Netherlands and Germany. A website communicating guidelines for the prevention and control of Methicillin Resistant Staphylococcus aureus served as a casus. The HCWs, the majority of whom had prior experience with the website, were asked to give their opinions about factors that hinder or facilitate adoption of the website in practice. The interviews were based on the PRECEDE (Predisposing, Reinforcing, and Enabling Causes in Educational Diagnosis and Evaluation) model complemented by quality criteria for health-related websites. This model encompasses different categories of factors relevant to technology adoption in health care.

Results: A total of 361 interview statements were relevant to the four main categories of the PRECEDE model, yielding the following observations:
\end{abstract}

(1) Technological factors (72 statements): The usability, design, and relevance of the website were positively valued. The website enabled HCWs to access contextually relevant information quickly. The website's credibility was evaluated rather negatively, as respondents perceived that the website's guidelines were not in concurrence with the best available evidence and it was not clear to HCWs who created the website.

(2) Individual factors (85 statements): Respondents, particular infection control professionals, showed individual resistance to the website because they preferred to use their personal knowledge and experience (and communication with colleagues) over online sources.

(3) Work-related factors (53 statements): Respondents perceived high work pressure during working hours as an impediment to consulting the website. In contrast, respondents thought the website might lower work pressure for infection control professionals, as they will receive fewer questions from HCWs.

(4) Organizational factors (131 statements): Interpersonal (face-to-face) communication between HCWs from different occupational groups in both a formal (training) and informal (feedback) manner was seen as the most stimulating factor behind website use. The respondents identified infection control nurses as the most important opinion leaders.

\footnotetext{
* Corresponding author. Tel.: +31 53489 4441; fax: +31 534894259.

E-mail address: f.verhoeven@utwente.nl (F. Verhoeven). 
Conclusion: Factors from multiple categories determine HCWs' adoption of web-based guidelines, but the organization appeared to be a paramount reinforcer of initiation and maintenance of technology adoption among HCWs. In order eliminate resistance and create ownership among HCWs toward the website, leading to a willingness to integrate the website into routine care, it is essential to more actively involve HCWs in the early phases of the design process.

๔ 2009 Elsevier Ireland Ltd. All rights reserved.

\section{Introduction}

Health care-associated infections cause thousands of preventable deaths each year [1]. It is therefore crucial that health care workers (HCWs) adhere to infection control guidelines. Although most HCWs are aware of the rationale for infection control practices, adherence to guidelines is generally poor [2]. This is partly due to problems with guidelines' usability [3]. A possible solution to this problem is to communicate guidelines via a website. A website enables the use of hyperlinks to additional resources and the use of multimodal functionalities, such as instructional videos. Consequently, in-depth information can be made available without affecting guidelines' readability [4]. Moreover, web-based guideline communication has the potential to combine information on relevant activities by facilitating information seeking and retrieval processes in order to provide high-quality and appropriate answers to specific clinical questions, which is the most common reason that HCWs use the Internet [5,6]. Therefore, HCWs' adherence is better to electronic guidelines than to paper guidelines [7]. Other reported benefits of web-based guideline communication are decreased practice variations between clinicians $[8,9]$ and improved patient outcomes $[9,10]$.

Despite the proven value of web-based guidelines, numerous obstacles to the adoption of web-based guidelines in daily work practice remain [5]. In this paper, adoption refers to the process by which individuals and groups decide to use a communication medium like a website for the retrieval of infection control guidelines. Adoption is a prerequisite for successful implementation of a website with infection control guidelines in health care settings [11]. Previous studies found several factors that may hinder the adoption of web-based guidelines, including lack of a computer connection in the HCW's office and fear that using such guidelines might interfere with the direct patient-physician relationship. HCWs are also concerned about the relevance and accuracy of instructions and the inability of web-based guidelines to adapt to varied situations [5,12]. Despite the identification of these adoption barriers, specific intervention steps for effective implementation of web-based guideline communication are not yet available. As systematic reviews have shown that intervention strategies taking into account micro, meso, and macro factors are most likely to be successful [13], we investigated the determinants of HCWs' adoption of web-based guideline communication from a multi-faceted perspective.

Several models have been used to examine technological adoption, and all have their foundation in Rogers' classical diffusion of innovation model. Examples include SocialCognitive theory, the Technology Acceptance Model, and the
Unified Theory of Acceptance and Use of Technology (UTAUT) [14]. Each of these models identifies three major categories of factors: individual characteristics (micro), such as a reluctance to change; work-related characteristics (meso, e.g., sufficient staff and time); and organizational characteristics (macro) like support from peers or superiors [15-19]. Most models assign equal importance to the influence of each of these three categories of factors on adoption. However, considering that successful adoption of a new technology in health care implies changes in the organization, technology, and people involved, it is important to examine such phenomena from a social interactionist perspective, which implies that the three aforementioned categories of factors mutually reinforce one another. For instance, efforts to motivate HCWs to adopt web-based guideline communication may fail if the ward's management is not supportive. The PRECEDE (Predisposing, Reinforcing, and Enabling Causes in Educational Diagnosis and Evaluation) model recognizes that factors at each of the three categories of factors are interrelated and each are situated on another hierarchical rank [15]. While other models assume the three separate categories of factors only have direct effects on intended behavior, the PRECEDE model suggests that there is also an indirect effect of organizational factors (macro) like management values or interpersonal communication on behavior. Moreover, these effects are mediated by work-related (meso) and individual (micro) factors (see Fig. 1). Therefore, we deem the PRECEDE model as appropriate to studying barriers and facilitators of web-based adoption of guideline communication among HCWs.

A fourth category that seems to be neglected by existing technology acceptance models concerns the characteristics of the technology itself. Particularly when communicating clinical guidelines, technological considerations are of vital importance in ensuring that the information presented is accurate, complete, and readable. Moreover, the website or system communicating the guidelines should be easy to use $[20,21]$. Therefore, we complemented the PRECEDE model with a fourth category of factors comprising quality characteristics

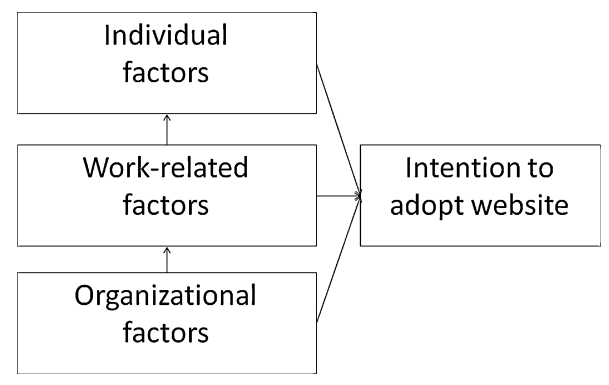

Fig. 1 - PRECEDE model. 
Table 1 - Conceptual framework for barriers and facilitators in health care workers' adoption of web-based guideline communication.

\begin{tabular}{|c|c|c|}
\hline Category & Factors & Description \\
\hline \multirow[t]{6}{*}{ Website quality } & Accuracy & $\begin{array}{l}\text { Degree to which information provided by the website is in } \\
\text { concurrence with the best evidence, as perceived by the individual }\end{array}$ \\
\hline & Completeness & $\begin{array}{l}\text { Degree to which information provided by the website comprises } \\
\text { necessary parts, elements, or steps to make a decision in daily } \\
\text { practice, as perceived by the individual }\end{array}$ \\
\hline & Readability & $\begin{array}{l}\text { Degree of complexity, and lengthiness of sentences of the provided } \\
\text { information on the website, as perceived by the individual }\end{array}$ \\
\hline & Design & Visual aspects of the website layout, as perceived by the individual \\
\hline & References provided & $\begin{array}{l}\text { Degree to which the individual is referred to other information } \\
\text { sources on the website, as perceived by the individual }\end{array}$ \\
\hline & Disclosures & $\begin{array}{l}\text { The degree to which information about terms of use, copyright, links } \\
\text { to other sites, and liability is provided by the website, as perceived by } \\
\text { the individual }\end{array}$ \\
\hline \multirow[t]{2}{*}{ Predisposing (individual) } & Attitude & $\begin{array}{l}\text { The value or benefit anticipated from the website relative to current } \\
\text { practice, as perceived by the individual }\end{array}$ \\
\hline & Personality & $\begin{array}{l}\text { The degree to which an individual health care worker shows initiative } \\
\text { to try new things such as the website }\end{array}$ \\
\hline \multirow[t]{4}{*}{ Enabling (work-related) } & Workload & $\begin{array}{l}\text { The degree to which the amount of work needed to be performed is } \\
\text { feasible within a specific period, and whether the website is } \\
\text { compatible with this amount of work }\end{array}$ \\
\hline & Tacit knowledge & $\begin{array}{l}\text { Knowledge that is context-dependent and made up of the practical } \\
\text { and experiential wisdom of individuals in concurrence or in contrast } \\
\text { with guidelines provided by the website }\end{array}$ \\
\hline & Infrastructure & $\begin{array}{l}\text { The presence of some form of infrastructure (computers, Internet } \\
\text { connection) or of other technologies in the ward, which cluster with } \\
\text { the website }\end{array}$ \\
\hline & Work experience & $\begin{array}{l}\text { Degree to which the individual has become experienced with various } \\
\text { technologies (such that the website can more easily coexist in daily } \\
\text { work practice) }\end{array}$ \\
\hline \multirow[t]{4}{*}{ Reinforcing (organizational) } & Management values & $\begin{array}{l}\text { Degree to which the opinion of an individual is respected or listened } \\
\text { to by others in terms of the adoption of the website }\end{array}$ \\
\hline & Training/feedback & $\begin{array}{l}\text { The degree to which individuals obtain the opportunity to learn and } \\
\text { discuss how and why to apply the website }\end{array}$ \\
\hline & Communication channels & $\begin{array}{l}\text { The paths through which opinion leaders and others communicate } \\
\text { about the website (benefits and drawbacks) }\end{array}$ \\
\hline & Subjective norm & $\begin{array}{l}\text { Rules, formal hierarchies, and informal mechanisms of } \\
\text { communication operative in the social system (the ward) that might } \\
\text { influence individual health care workers' adoption of the website }\end{array}$ \\
\hline Behavioral intention & & The individual health care worker's readiness to adopt the website \\
\hline
\end{tabular}

of health-related websites [20] and used this as the conceptual framework for our study (see Table 1).

The aim of this study is to identify any major factors and their interrelationship that could affect HCWs' adoption of a website for communicating infection control guidelines, and to use the findings to stimulate adoption of the website by HCWs in daily work practice.

\section{Methods}

\subsection{Research context}

Due to increased international trade in health services, Methicillin Resistant Staphylococcus aureus (MRSA) is one of the organisms that most commonly contribute to the rapid spread of health care-associated infections [1]. The Dutch-German research project EUREGIO MRSA-net Twente/Münsterland addresses this problem at a cross-national level, and the study reported here was conducted as part of this project [22]. This study took place between April and June 2008.

This study focuses on the adoption of a website comprising MRSA guidelines. The website (www.mrsa-net.nl) was launched in February 2008 and was gradually developed following a specific user-centered design procedure [23]. First, 28 scenario-based tests were conducted during which HCWs used paper-based guidelines to solve MRSA-related questions. The detected problems gave input to the website's structure and content. Second, a Card Sort Task $(n=10)$ generated the website's menu structure and prototyping interviews $(n=14)$ led to the website's final lay-out. Based on the results, the first working prototype was developed and tested formatively by conducting scenario-based tests again $(n=28)$ before the website's launch. In each phase of this user-centered design process, the sample included physicians, nurses, and nursing assistants. Before the website's official launch, a workshop 
Table 2 - Two examples of question-answer pairs that can be found on the website communicating Methicillin Resistant Staphylococcus aureus guidelines.

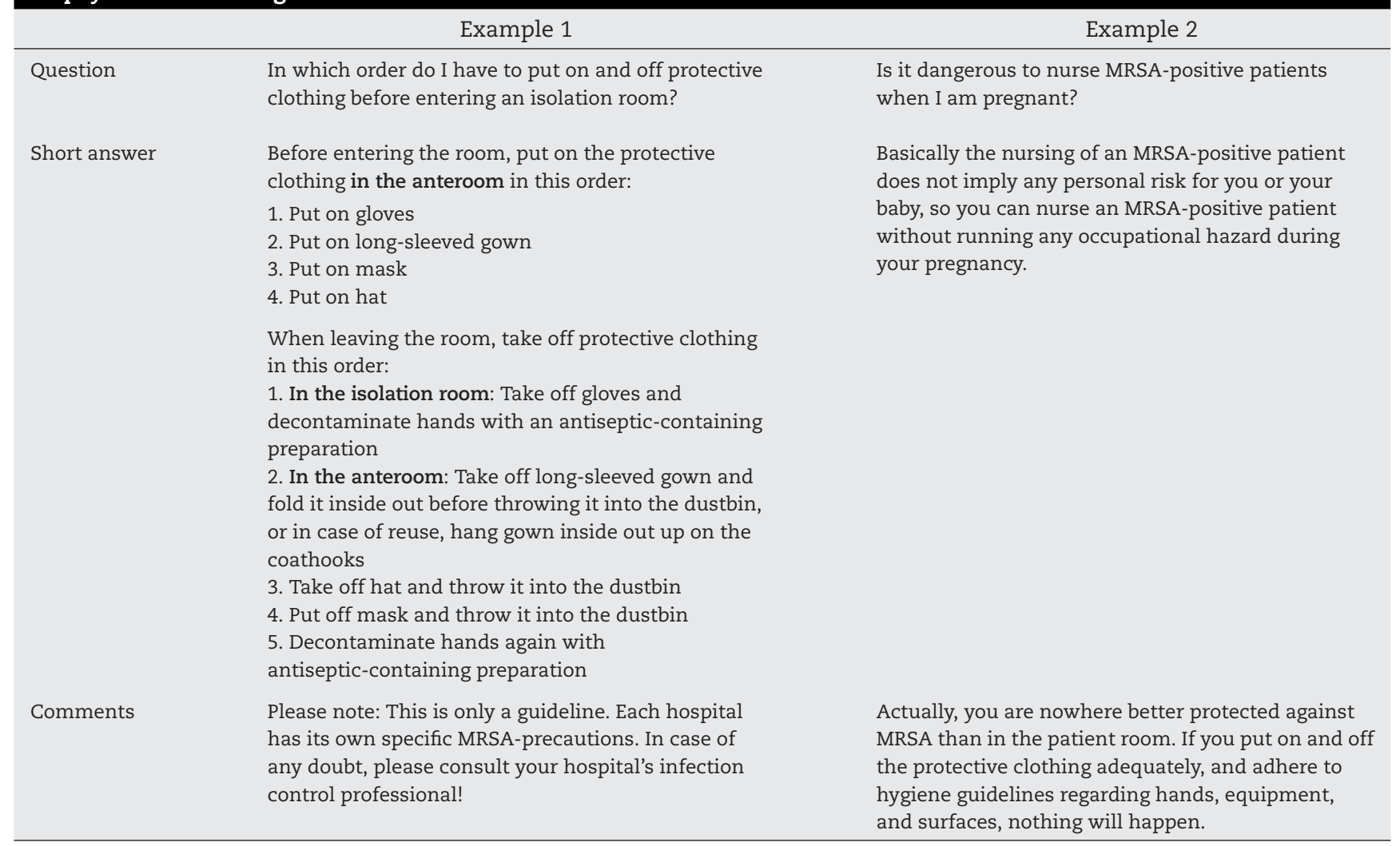

was held among infection control professionals to gather their opinion. During this workshop, a working prototype of the website was demonstrated by the researcher (FV). The goal of this workshop was for the researcher to learn from the infection control professionals' feelings and attitudes about the website, and to generate a sense of involvement among the infection control professionals toward the website. The workshop generated several crucial issues for improvement. For instance, the infection control professionals suggested that the website's objective should be clearly present on the website. Therefore, we added a button "About this website" on the website. Also, infection control professionals argued that we needed to add more pictures and videos. All relevant topics that were raised during the workshop were solved before the website was officially launched online.

The bilingual website presents current, national MRSA guidelines $[24,25]$ presented as answers to questions that reflect HCWs' practical informational needs, as defined in the first scenario-based study (see Table 2 for two examples) [26]. Each answer comprises a title, a short answer, an instructional video, comments, references (e.g., newspaper articles, links to other websites) for further reading, and (multi-media) examples. Three search options (a search engine, ten categories representing over 200 questions, and a list of frequently asked questions) and a breadcrumb trail facilitate HCWs to find relevant information on the website. Figs. 2 and 3 contain a screen capture of the website, illustrating the search options and the answer structure. Since its launch, the website has been consulted daily by approximately 450 unique visitors. Although the questions on both the Dutch and German part of the website are identical, the answers have to be country-specific due to differences in national MRSA-policy. For example, in the Netherlands, surveillance cultures are taken upon hospital admission from people who are in close contact with living pigs and calves, in contrast to Germany. ${ }^{1}$ Therefore, answers were based on the country's national MRSA guidelines and complemented and validated by a medical microbiologist from the concerned country [24,25].

No particular accreditation system for health-related websites, such as the Health on the Net (HON)-code, has yet been successfully determined in the Netherlands and Germany. To assure credibility of the website's content, we used the national MRSA guidelines that are considered professional standards and are used as such by the Public Health Inspector

\footnotetext{
${ }^{1}$ Although the MRSA prevention and control policies across countries worldwide are comparable on the whole (e.g., see C.A. Muto, J.A. Jernigan, B.E. Ostrowsky, H.M. Richet, W.R. Jarvis, J.M. Boyce, et al. SHEA guidelines for preventing nosocomial transmission of multidrug-resistant strains of Staphylococcus aureus and Enterococcus. Infect. Control Hosp. Epidemiol. 24 (5) (2003) 362-386.), there are subtle differences among countries. Particularly in the Netherlands, the MRSA policy has a specific "search and destroy" character, comprising rigid isolation and screening of high-risk patient groups, screening low-risk groups, strict isolation of carriers, and treatment of people carrying MRSA. This "search and destroy" is not enforced in Germany. Therefore, the answers on the German and Dutch part of the website could not be formulated identically.
} 


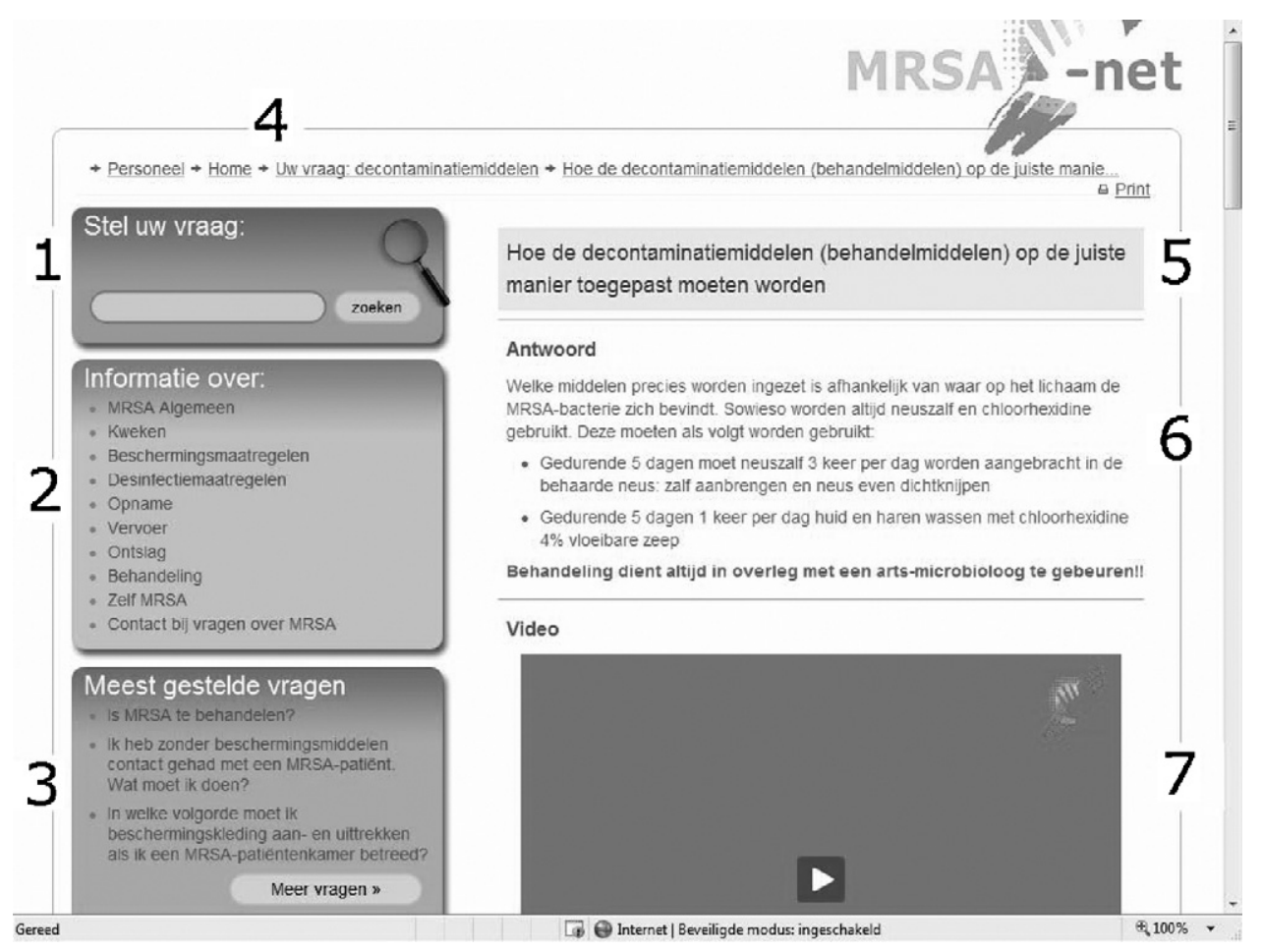

Fig. 2 - Screen capture 1 of the website communicating Methicillin Resistant Staphylococcus aureus guidelines. Note: 1 = search engine; 2 = categories; 3 = frequently asked questions; 4 = breadcrumb trail; 5 = answer title; 6 =short answer; 7 = video .

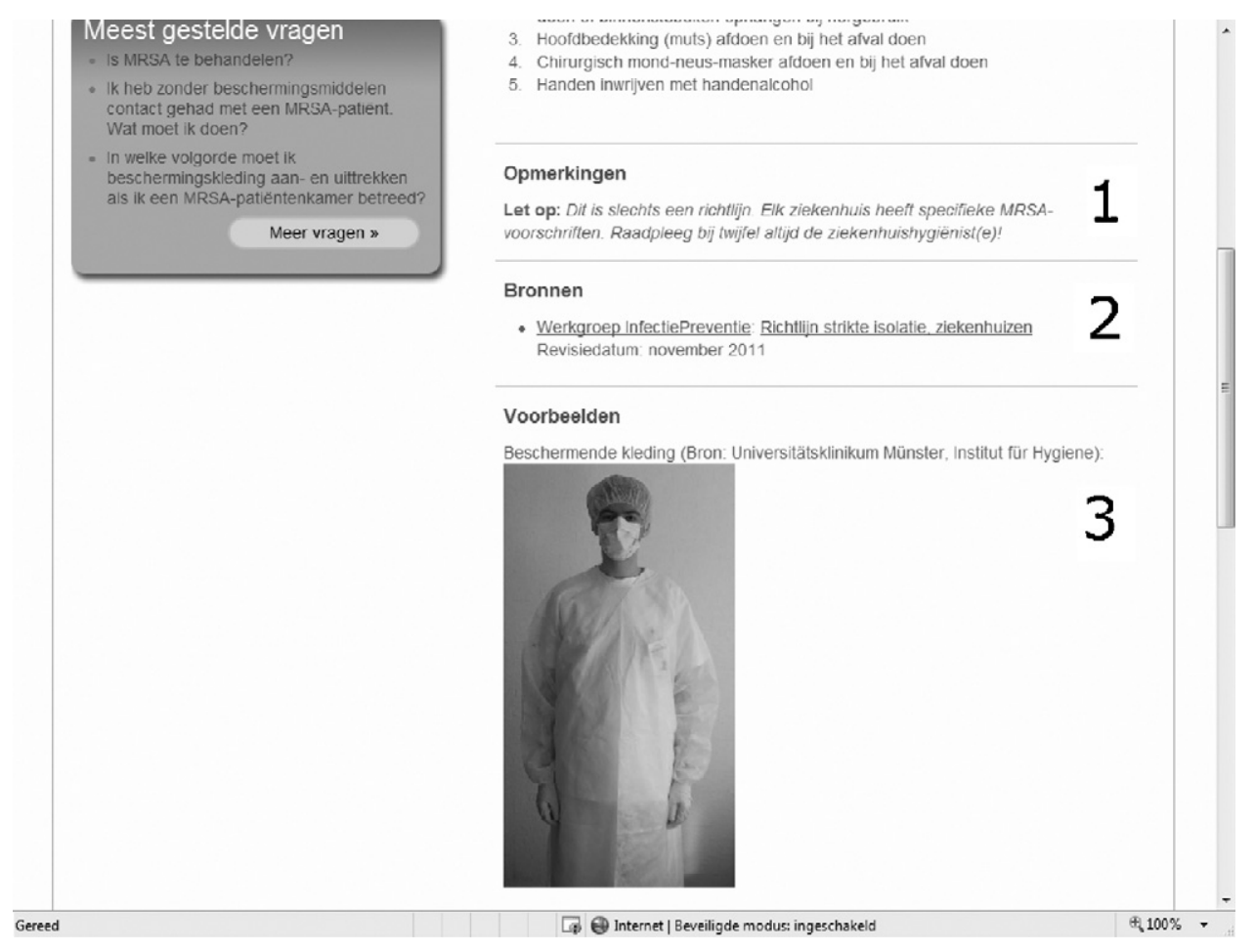

Fig. 3 - Screen capture 2 of the website communicating Methicillin Resistant Staphylococcus aureus guidelines. Note: 1 = comments; 2 = references; 3 = examples. 
Table 3 - Interview guide with open-ended questions to identify barriers and facilitators in health care workers' adoption of web-based guideline communication.

\begin{tabular}{|c|c|c|}
\hline Category & Factor & Factors and questions \\
\hline Website quality & Website quality & $\begin{array}{l}\text { 1. } \\
\text { - Do you think that the information on the website is in concurrence } \\
\text { with the best evidence? (accuracy) } \\
\text { - Do you think that the information provided by the website contains } \\
\text { the necessary parts to make a decision in daily practice? (completeness) } \\
\text { - What do you think of the complexity and lengthiness of sentences of } \\
\text { the information on the website? (readability) } \\
\text { - How would you rate the design of the website? (design) } \\
\text { - What do you think of the references to other information sources on } \\
\text { the website? (references provided) } \\
\text { - To what degree do you perceive that information about terms of use, } \\
\text { copyrights, and liability is provided on the website? (disclosures) }\end{array}$ \\
\hline \multirow[t]{2}{*}{ Predisposing (individual) } & Attitude & $\begin{array}{l}\text { 2. Do you think the website would be useful for you in daily work } \\
\text { practice, or for other target groups? What possible benefits and threats do } \\
\text { you perceive? }\end{array}$ \\
\hline & Personality & $\begin{array}{l}\text { 3. Do you think personality characteristics (e.g., self-direction, } \\
\text { conformity) will affect use of the website in daily practice? }\end{array}$ \\
\hline \multirow[t]{4}{*}{ Enabling (work-related) } & Workload & 4. Do you believe workload will impede or stimulate use of the website? \\
\hline & Tacit knowledge & $\begin{array}{l}\text { 5. How would you rate your current knowledge level regarding MRSA } \\
\text { guidelines, and to what degree will this influence use of the website? }\end{array}$ \\
\hline & Infrastructure & $\begin{array}{l}\text { 6. Do you think the presence of infrastructure (e.g., computers with } \\
\text { Internet connection) on your ward will affect website use? How? }\end{array}$ \\
\hline & Work experience & $\begin{array}{l}\text { 7. How would you rate your experience with using technology in your } \\
\text { work setting and do you expect this to hinder or facilitate website use? }\end{array}$ \\
\hline \multirow[t]{4}{*}{ Reinforcing (organizational) } & Management values & $\begin{array}{l}\text { 8. Does your ward employ any individuals whose opinions are respected } \\
\text { or even just listened to by others? Who are these individuals and how can } \\
\text { they possibly affect website use? }\end{array}$ \\
\hline & Training/feedback & $\begin{array}{l}\text { 9. Is there any mechanism of frequent safety-related feedback or training } \\
\text { by co-workers or supervisors present on this ward? If yes, how would this } \\
\text { influence use of the website among health care workers? }\end{array}$ \\
\hline & Communication channels & $\begin{array}{l}\text { 10. Which paths do you perceive to be the most effective in } \\
\text { communicating to health care workers about the website? }\end{array}$ \\
\hline & Subjective norm & $\begin{array}{l}\text { 11. Does your colleagues' behavior normally influence your behavioral } \\
\text { intentions, and to what degree do you think this will affect your intention } \\
\text { to use the website? }\end{array}$ \\
\hline Behavioral intention & Behavioral intention & $\begin{array}{l}\text { 12. Do you intend to use the website in the near future in your daily work } \\
\text { practice? Why (not)? }\end{array}$ \\
\hline
\end{tabular}

in both Germany and the Netherlands [24,25]. Next, we applied the basic quality criteria for guideline communication, as defined by the International Organization for Standardization [27]. For the website's presentation, we applied researchbased web design and usability guidelines provided by the US Department of Health and Human Services [28].

\subsection{Sample}

Respondents $(n=20)$ were employees of hospitals in the Euregio Twente/Münsterland, and represented the website's main target groups: nursing assistants, nurses, physicians, infection control nurses, and medical microbiologists. The sample comprised four representatives from each target group. Respondents were selected from a list provided by the infection control nurses at all hospitals in the Euregio Twente/Münsterland. Ultimately, the study was conducted in two Dutch hospitals (bed sizes 314 and 1070) and two German hospitals (bed sizes 405 and 1500). We selected these hospitals because together they represented several hospi- tal categories (urban, rural, teaching, and non-teaching). From each country, a rural non-teaching hospital was represented next to an urban teaching hospital. Besides, these hospitals were selected because of their location in the Dutch-German border region, where the research project EUREGIO MRSA-net Twente/Münsterland was carried out (see Section 2.1). Respondents had used the website before, and their mother tongue was either Dutch or German. Eight of the respondents were male, twelve were female. On average the respondents had been working in health care for 17.7 years (range $0.25-25)$, and in their current job for 7.6 years. The majority $(n=16)$ were full-time employees in their current job position.

\subsection{Measures}

An interview guide was constructed, based on the aforementioned conceptual framework. Open-ended questions were formulated in order to probe HCWs about their perceptions of the web-based guideline communication and their experiences with the website (see Table 3). Close-ended questions 
Table 4 - Barriers and facilitators for website adoption resulting from interview statements $(n=20)$.

\begin{tabular}{|c|c|c|c|}
\hline Category & Factors & $\begin{array}{l}\text { Category } \\
\text { number }\end{array}$ & $\begin{array}{l}\text { Categories (barriers and facilitators for } \\
\text { website adoption) }\end{array}$ \\
\hline \multirow[t]{15}{*}{$\begin{array}{l}\text { Website quality (72 } \\
\text { statements) }\end{array}$} & \multirow[t]{3}{*}{ Accuracy } & [1] & $\begin{array}{l}\text { + The guidelines provided by the website are in concurrence with } \\
\text { most actual guidelines available }(n=3)\end{array}$ \\
\hline & & [2] & $\begin{array}{l}\text { - The website does not mention the frequency with which guidelines } \\
\text { are updated }(n=3)\end{array}$ \\
\hline & & [3] & $\begin{array}{l}\text { - The guidelines provided by the website are not in concurrence with } \\
\text { the best available evidence }(n=3)\end{array}$ \\
\hline & Completeness & [4] & $\begin{array}{l}\text { + The website provides all necessary parts, elements, or steps for } \\
\text { making a decision about practice regarding MRSA }(n=4)\end{array}$ \\
\hline & \multirow[t]{2}{*}{ Readability } & [5] & $\begin{array}{l}\text { + The guidelines on the website are described concisely (adequate } \\
\text { word length and sentence length) }(n=3)\end{array}$ \\
\hline & & [6] & $\begin{array}{l}\text { + The guidelines on the website are described clearly (without } \\
\text { complexity) }(n=3)\end{array}$ \\
\hline & Design & [7] & + The website looks visually attractive (colors, pictures) $(n=7)$ \\
\hline & References provided & [9] & $\begin{array}{l}\text { + Each guideline on the website contains references to scientific } \\
\text { information and other sources, which enhances the website's } \\
\text { credibility }(n=5)\end{array}$ \\
\hline & Disclosures & [10] & $\begin{array}{l}\text { - The website does not mention which organization(s) developed the } \\
\text { website/wrote the guidelines }(n=3)\end{array}$ \\
\hline & \multirow[t]{3}{*}{ Usability } & [11] & + The website is easy to use $(n=6)$ \\
\hline & & [12] & $\begin{array}{l}\text { + The website enables health care workers to find relevant } \\
\text { information quickly }(n=5)\end{array}$ \\
\hline & & [13] & + The website is highly accessible for a broader target group $(n=4)$ \\
\hline & \multirow[t]{2}{*}{ Findability } & [14] & $\begin{array}{l}\text { + The website is among the top three hits in Google when entering } \\
\text { "MRSA" }(n=5)\end{array}$ \\
\hline & & [15] & $\begin{array}{l}\text { - There is a similar website about the same topic with almost an } \\
\text { identical URL (www.mrsa-net.org instead of www.mrsa-net.nl), which } \\
\text { is confusing }(n=3)\end{array}$ \\
\hline & Relevance & [16] & $\begin{array}{l}\text { + The website presents practical questions that are of major interest } \\
\text { to health care workers }(n=10)\end{array}$ \\
\hline \multirow[t]{13}{*}{$\begin{array}{l}\text { Predisposing (individual) } \\
\quad \text { (85 statements) }\end{array}$} & \multirow[t]{8}{*}{ Attitude } & [17] & $\begin{array}{l}\text { + The website enables health care workers to look up practical } \\
\text { information at any time and location }(n=5)\end{array}$ \\
\hline & & [18] & $\begin{array}{l}\text { + The website is the first that handles the topic in such a profound } \\
\text { manner, which enhances credibility }(n=7)\end{array}$ \\
\hline & & [19] & $\begin{array}{l}\text { + The website is valuable, with practical contributions to existing } \\
\text { local guidelines }(n=4)\end{array}$ \\
\hline & & [20] & $\begin{array}{l}\text { - Personal lack of interest in website content as it pertains to } \\
\text { infection control guidelines }(n=4)\end{array}$ \\
\hline & & [21] & - Personal resistance against Internet-related technologies $(n=5)$ \\
\hline & & [22] & $\begin{array}{l}\text { - The website is only of relevance for those who must actually } \\
\text { comply with the guidelines, such as nursing staff }(n=3)\end{array}$ \\
\hline & & [23] & $\begin{array}{l}\text { - The guidelines communicated by the website are not in } \\
\text { concurrence with locally enforced guidelines }(n=10)\end{array}$ \\
\hline & & [24] & $\begin{array}{l}\text { - The website cannot replace face-to-face contact; it can only serve as } \\
\text { an additional communication channel }(n=5)\end{array}$ \\
\hline & Personality & [25] & $\begin{array}{l}\text { + Self-direction is an important attribute that predisposes individual } \\
\text { health care workers to try out new things, such as the website }(n=4)\end{array}$ \\
\hline & \multirow[t]{4}{*}{ Target group } & [26] & + The website is useful for nurses $(n=12)$ \\
\hline & & [27] & + The website is useful for patients $(n=14)$ \\
\hline & & [28] & + The website is useful for patients' relatives $(n=6)$ \\
\hline & & [29] & + The website is useful for physicians $(n=6)$ \\
\hline \multirow[t]{2}{*}{$\begin{array}{l}\text { Enabling (work-related) } \\
\text { (53 statements) }\end{array}$} & \multirow[t]{2}{*}{ Workload } & [30] & $\begin{array}{l}\text { + The website lowers work pressure for infection control } \\
\text { professionals, as they will receive fewer questions from health care } \\
\text { workers }(n=3)\end{array}$ \\
\hline & & [31] & $\begin{array}{l}\text { - High work pressure impedes consulting the website during working } \\
\text { hours }(n=9)\end{array}$ \\
\hline
\end{tabular}


Table 4 (Continued)

\begin{tabular}{|c|c|c|c|}
\hline Category & Factors & $\begin{array}{l}\text { Category } \\
\text { number }\end{array}$ & $\begin{array}{l}\text { Categories (barriers and facilitators for } \\
\text { website adoption) }\end{array}$ \\
\hline & Tacit knowledge & $\begin{array}{l}{[32]} \\
{[33]}\end{array}$ & $\begin{array}{l}\text { + The website enables health care workers with lack of knowledge of } \\
\text { MRSA guidelines to retrieve relevant information }(n=4) \\
\text { - Personal, practical, and experiential wisdom about MRSA guidelines } \\
\text { leads health care workers to not need the website }(n=10)\end{array}$ \\
\hline & Infrastructure & [34] & $\begin{array}{l}\text { - The absence of computers with Internet connections in the work } \\
\text { environment impedes health care workers from consulting the } \\
\text { website during working hours }(n=7)\end{array}$ \\
\hline & Work experience & [35] & $\begin{array}{l}\text { + The website easily fits into daily work practices since health care } \\
\text { workers have become experienced with technology }(n=17)\end{array}$ \\
\hline & & [36] & $\begin{array}{l}\text { - If there is no immediate cause for website use during work practice, } \\
\text { health care workers will forget about the website's existence }(n=3)\end{array}$ \\
\hline \multirow{17}{*}{$\begin{array}{l}\text { Reinforcing } \\
\text { (organizational) (131 } \\
\text { statements) }\end{array}$} & Management values & [37] & $\begin{array}{l}\text { + Infection control nurses are the most important and adequate } \\
\text { opinion leaders to advocate website adoption }(n=10)\end{array}$ \\
\hline & & [38] & $\begin{array}{l}\text { + Ward management is the most important and adequate opinion } \\
\text { leader in general, including for website adoption }(n=5)\end{array}$ \\
\hline & & [39] & $\begin{array}{l}\text { - Opinion leaders will not influence the behavioral intentions of } \\
\text { individual health care workers to use the website, as health care } \\
\text { workers are self-directive }(n=8)\end{array}$ \\
\hline & & [40] & $\begin{array}{l}\text { - Infection control nurses are not effective opinion leaders to } \\
\text { promote website use, as they are not respected or listened to (as they } \\
\text { always "bring bad news") }(n=3)\end{array}$ \\
\hline & Training/feedback & [41] & $\begin{array}{l}\text { + Obligatory training sessions are the best way to bring the website to } \\
\text { health care workers' attention }(n=13)\end{array}$ \\
\hline & & {$[42]$} & $\begin{array}{l}\text { + Enabling health care workers to actually use the website during } \\
\text { obligatory training sessions is the best way to predispose them } \\
\text { favorably }(n=6)\end{array}$ \\
\hline & & [43] & $\begin{array}{l}\text { - Training sessions solely about the website, which health care } \\
\text { workers have to attend on a voluntary basis, will have no effect }(n=3)\end{array}$ \\
\hline & Communication channels & [44] & $\begin{array}{l}+ \text { Mutual recommendation of the website among health care workers } \\
\text { is the best way to stimulate adoption }(n=12)\end{array}$ \\
\hline & & [45] & $\begin{array}{l}+ \text { A leaflet is an appropriate communication channel to promote } \\
\text { website use among health care workers }(n=10)\end{array}$ \\
\hline & & [46] & $\begin{array}{l}+ \text { A team meeting is an appropriate communication channel to } \\
\text { promote website use among health care workers }(n=10)\end{array}$ \\
\hline & & [47] & $\begin{array}{l}\text { A personal approach to health care workers by the website project } \\
\text { team is an appropriate communication channel to promote website } \\
\text { use among health care workers }(n=6)\end{array}$ \\
\hline & & [48] & $\begin{array}{l}\text { + A link in existing, locally enforced guidelines is an appropriate } \\
\text { communication channel to promote website use among health care } \\
\text { workers }(n=5)\end{array}$ \\
\hline & & [49] & $\begin{array}{l}\text { + An e-mail to all health care workers is an appropriate } \\
\text { communication channel to promote website use among health care } \\
\text { workers }(n=5)\end{array}$ \\
\hline & & [50] & $\begin{array}{l}\text { - An e-mail to all health care workers to promote the website will } \\
\text { have no effect due to e-mail overload and spam }(n=4)\end{array}$ \\
\hline & & [51] & $\begin{array}{l}\text { - Consulting a co-worker is more efficient than looking up guidelines } \\
\text { on a website }(n=11)\end{array}$ \\
\hline & Subjective norm & [52] & $\begin{array}{l}\text { + Coworkers' opinion affects an individual health care workers' } \\
\text { intentions to adopt the website }(n=8)\end{array}$ \\
\hline & & [53] & $\begin{array}{l}\text { - Coworkers' opinions will not affect an individual health care } \\
\text { workers' intention to adopt the website }(n=12)\end{array}$ \\
\hline \multirow{3}{*}{$\begin{array}{l}\text { Behavioral intention }(20 \\
\text { statements) }\end{array}$} & & [54] & $+\mathrm{I}$ will (continue) to use the website $(n=12)$ \\
\hline & & [55] & - I will not (continue to) use the website $(n=4)$, \\
\hline & & [56] & - I do not know yet whether I will (continue to) use the website $(n=4)$ \\
\hline
\end{tabular}

${ }^{a}$ Mentioned by at least three different respondents. +: stands for facilitator, -: for barrier. 
can only confirm known variables and assess their scores [29]. Since we were primarily interested in exploring the practical meaning HCWs gave to theoretical concepts in order to tailor adoption-enhancing intervention strategies to HCWs' current realm, rather than testing a number of propositions, we opted to conduct interviews with open-ended questions. The questions represented the factors inherent in the PRECEDE model (attitude, personality, workload, tacit knowledge, infrastructure, work experience, management values, training and feedback, communication channels, and subjective norms), in addition to questions about website quality and intentions to adopt the website in practice. The questions were derived from several existing, validated instruments fitting the study's themes [15-18]. The face validity of the interview guide was tested by piloting it face-to-face with one Dutch and one German medical microbiologist involved in the research project (not included in the sample). Also, we determined inter-rater reliability during data analysis to verify whether the questions were actually appropriate for measuring the factors from our conceptual framework.

\subsection{Procedure}

The interviews were conducted by an interviewer who spoke fluent Dutch and German. The interviewer brought a laptop with an offline version of the website to the interview location in case the respondent needed a reminder of the website. The purpose and procedure of the interview were described in general terms at the beginning of each interview. Then the interview began with the interviewer following the interview scheme as presented in Table 3. The interview ended when the interviewer perceived that the four major categories of the conceptual framework were exhausted and no new information could be expected. The interviews lasted between 45 and $75 \mathrm{~min}$. The interviews were audiotaped with prior consent of all respondents and transcribed verbatim afterwards.

The study was approved by the management of the hospitals in which the respondents were employed. Respondents gave oral consent to participate and for recording the interviews with a digital voice recorder. We emphasized that the respondents' contribution would be strictly confidential and that data would be immediately destroyed after data transcription.

\subsection{Analysis}

Data from one randomly selected transcribed interview were analyzed by two coders (FV, LvG) using deductive analysis, implying that the coding categories were derived from the conceptual framework presented in Table 1 [30]. Four new themes emerged during the coding process (relevance, findability, usability, and target group) that could not be assigned to one of the categories from the framework. Therefore, these themes were added to the coding scheme. Subsequently, all transcribed data were coded by means of the revised framework. Repeated or reworded descriptions of the same factors were counted only once per interview.

During the interviews, respondents not only expressed their opinions toward website use but also with respect to guideline adherence. Only statements about website adop- tion were included in the analysis. Overall, 575 statements about guideline adherence and website adoption were identified and coded by a single coder. Then another researcher coded a random selection of $10 \%$ of all coded fragments. Both (Dutch) researchers had an excellent command of the German language. Therefore, Dutch and German data were analyzed in their original wordings without translating all data into a similar language. Agreement on categorization of problems and requirements was satisfactory (Cohen's Kappa =0.82) [31]. All data were analyzed by hand, without the use of qualitative data analysis software. Although we are aware of the benefits that data analysis software for qualitative research might have, we opted to analyze the data by hand for two reasons. First, the bilingual character of the data set hampered the ease of applying data analysis software. Second, we feared that by using data analysis software, the volume and breadth of the categories would become overemphasized, at the cost of depth and meaning of the measured constructs (rich meanings would be turned down into meaningless numbers).

After coding, (nearly) synonymous statements were combined into more general subthemes in order to create a better-organized overview of the results. The subthemes that emerged are presented in Table 4 in Section 3.

\section{Results}

Table 4 reflects the opinions of HCWs' about website adoption as they emerged from the interview statements. Only issues that were mentioned by at least three different respondents are included. This section will elaborate on the most frequently mentioned factors, separated into each category of factors of the conceptual framework.

\subsection{Statements related to website quality}

\subsubsection{Website's general appreciation}

Respondents were generally positive toward the quality of the website. Out of 72 statements, 60 were positive and 12 were negative. Positive statements mainly concerned the website's relevance $(n=10)$, design $(n=12)$, and usability $(n=15)$.

With regard to relevance, the website's practical approach to infection control guidelines was appreciated in particular $(n=10)$ :

"Questions from daily life, about which you generally do not think of. Answered in great detail." (German infection control nurse; see Table 4, Category 16)

\subsubsection{Website's design and usability}

The website's design was perceived as good due to its visual attractiveness $(n=7)$ and convenient arrangement of information $(n=5)$. Respondents pointed positively to the website's usability, which was easy to use $(n=6)$, accessibility for a broad target group $(n=4)$, and the way that it enabled them to find relevant information quickly $(n=5)$ :

"Especially the search engine [..] when it functions well, and one hits the mark by entering the right keywords, then it is really easy." (German physician; see Table 4, Category 12) 


\subsubsection{Website's accuracy and disclosures}

On the contrary, respondents were more negative about the website's accuracy and disclosures, which seemed to negatively affect the website's credibility $(n=9)$. It was not clear to respondents $(n=3)$ how often information on the website is updated, and they also missed sound evidence that the website's guidelines were in accordance with the best available evidence $(n=3)$. Furthermore, credibility was seen as a problem because it was not obvious who created the website $(n=3)$. One respondent suggested to acquire accreditation to enhance the website's credibility.

\subsection{Statements related to predisposing (individual) factors}

\subsubsection{Website's target group}

Table 4 shows that 85 statements concerned individual factors, of which 58 were positive and 27 were negative. The majority of positive statements concerned respondents' ideas about the target group to whom the website would be most useful $(n=38)$. Respondents agreed that patients $(n=14)$ and nurses $(n=12)$ would benefit most from the website. Nursing staff perceived the website as useful because "this website is the first that handles the topic in such a profound manner," which enhances the website's credibility $(n=7)$, and "the practical information on the website complements the guidelines enforced at their hospital" $(n=4)$.

\subsubsection{Attitude toward the website}

43 Statements were related to respondents' attitudes toward using the website. The majority of these statements $(n=27)$ were negative, and prevailed particularly among medical professionals (microbiologists and physicians). Negative attitudes involved resistance to web-based technologies $(n=5)$ and doubts about a possible discrepancy between guidelines communicated by the website and guidelines locally enforced $(n=10)$ :

"Each hospital has its own specific guidelines for particular situations. For instance, we don't have short-sleeved gowns for physicians, in contrast to what the website recommends." (German medical microbiologist, see Table 4, Category 23)

Another subject of concern, in the respondents' opinion, was that the website can never replace face-to-face communication $(n=5)$ :

"I assume it is better that when the nurse has time, and the physician has time, to answer such questions in a personal conversation. You cannot leave the worker with 'Google it yourself!"' (German medical microbiologist; see Table 4, Category 24)

\subsubsection{Personality}

Another individual factor emerging from the interviews was personality. Four respondents expressed that "self-willed people are more inclined to try new things, such as the website" (see Table 4, Category 25).

\subsection{Statements related to enabling (work-related) factors}

\subsubsection{Tacit knowledge}

Compared to the other categories of factors, respondents expressed relatively few statements concerning work-related factors. The majority of the 53 statements were negative $(n=29)$. Ten respondents perceived no need for the website, as they had already become skilled in performing the measures $(n=10)$.

\subsubsection{Infrastructure}

Other negative statements involved a lack of computers with an Internet connection on the ward $(n=7)$ and high work pressure $(n=9)$, both of which would hinder consulting the website during working hours.

\subsubsection{Work experience and workload}

Conversely, almost all respondents $(n=17)$ indicated that "the website can easily coexist in daily work practices, as HCWs have become experienced with technology" (Table 4, Category 35). Even more contradictory to the finding that high work pressure impedes website use was that three respondents claimed the website could actually decrease infection control staff's workload:

"It saves us a lot of phone calls, actually. Actually you take away some of our work." (Dutch infection control nurse; see Table 4, Category 30)

\subsection{Statements related to reinforcing (organizational) factors}

Of all 361 statements that can be found in Table 4, one third involved reinforcing factors. In contrast to the work-related and individual factors, about which respondents were mainly negative, respondents assigned a more positive role to the organization: 90 of 131 statements were positive.

\subsubsection{Training and feedback}

Respondents were particularly favorable about the opportunity to promote the website during obligatory training sessions $(n=13)$ :

"We are able to rush through a lot of topics, for instance MRSA. We discuss the hospital's MRSA-rate, the main points, the ward, and the measures. And then we also discuss the website, we project it on the wall with a beamer and everyone can see it." (German infection control nurse; see Table 4, Category 41)

\subsubsection{Management values}

Training courses are usually conducted by an infection control nurse. Half of the respondents indicated the infection control nurse to be the most influential person stimulating website use $(n=10)$. However, this positive influence of the infection control nurse was played down by eight respondents (all physicians or medical microbiologists) who expressed that infection control nurses have no influence on their behavior: "what she thinks does not matter," or "I don't care what she believes" (see Table 4, Categories 39 and 40). 
Table 5 - Overview of main study findings, resulting from interview statements $(n=20)$.

Category

Website quality $(72$ statements

Predisposing (individual) (85 statements)

Enabling (work-related) (53 statements)

Reinforcing (organizational) (131 statements)

Behavioral intention (20 statements)
Main findings

- The usability and design were positively valued, next to the contextual relevance of the website's information.

- The credibility of the website was negatively valued because it is not clearly stated whether the website's guidelines are in concurrence with the best available evidence. Next, the website's source is not obviously disclosed.

- HCWs, particularly infection control professionals, might encounter resistance toward the website because they prefer to use their personal knowledge and experience and communication with colleagues over online sources.

- High work pressure possibly impedes website use during work hours.

- On the other hand, website use might decrease work pressure for infection control professionals.

- Interpersonal (face-to-face) communication between HCWs from different occupational groups in both a formal (training) and informal (feedback) manner is the most stimulating factor for website use.

- Infection control nurses are the most important opinion leaders to advocate website use.

- HCWs are willing to use the website in the future, unless they already are familiar with the content or feel resistance against funding practical decisions on information from a website.

\subsubsection{Communication channels and subjective norm}

Furthermore, respondents were positive about the role of personal communication. Twelve respondents, of whom eight were nursing staff, perceived personal recommendations of the website among HCWs as an effective way to stimulate website use, as their colleagues' opinions influence their behavior, including website use $(n=8)$. Also, a personal approach from the website's project team was positively valued $(n=6)$ :

"Last week there was a meeting [. . . ] and I attended it briefly. The nice thing about that was that I spoke to X [a member of the website's project team] (...) and he showed me the website. So now I have incorporated the website in my Favourites." (Dutch medical microbiologist; see Table 4, Category 47)

On the contrary, eleven respondents perceived personal contact as more efficient than using the website.

\subsection{Statements related to behavioral intention}

Most respondents expressed willingness to use the website in the near future $(n=12)$. Four indicated no intention to use the website because they "already knew the answers" $(n=2)$ or they supposed information on "a website does not fit the situation-dependent character of an MRSA policy" $(n=2)$. The four remaining respondents expressed uncertainty about their intentions to use the website.

\subsection{Summary of main findings}

In order to structure the results more conveniently, we summarized the main findings in Table 5.

\section{Discussion}

\subsection{Theoretical implications}

4.1.1. Personal intention to use the website

The results of this case study show that the usability, design, and relevance of the website were positively valued by its users. However, respondents were rather negative about the website's credibility. In particular, infection control professionals indicated that they would use the website only if there was enough guarantee that the guidelines on the website were in concurrence with the best available evidence (accuracy), and if elements like terms of use, links to other sources, and liability (disclosures) were clearly presented. This supports the finding from previous research that communicating clinical guidelines online requires a special focus on credibility $[5,12]$. Omitting credibility-enhancing features on a website might even lead to individual resistance among HCWs toward using the website, as 17 out of 43 interview statements about attitudes were related to credibility (see Table 4, Categories 18 and 23).

Next to credibility concerns, the personal intention to use the website was strongly affected by the experience and prior knowledge of HCWs, which consists of their practical and experiential wisdom. Ten HCWs, including all medical or infection control professionals, indicated that they already had become sufficiently skilled in performing the guidelines, and therefore did not need the website. Therefore, these occupational groups deemed the website to be useful only for nursing staff and patients, but not for themselves. This finding is not surprising, as technology adoption in health care has always been associated with resistance among HCWs with more strategic tasks [32,33]. Nursing staff might be more willing to conform, as their views of professionalism are bound up with adherence to rules and guidelines, and they are therefore more inclined to adopt web-based guidelines than are physicians and infection 
control staff. Physicians and infection control professionals, on the other hand, are trained to use clinical judgment, and are encouraged to make decisions on a case-by-case basis. They therefore may perceive rules communicated by a website as a threat to professional autonomy. However, in order eliminate resistance and create ownership among infection control professionals toward the website, leading to a willingness to integrate the website into routine care, it is essential to more actively involve infection control professionals in the early phases of the design process $[3,23]$.

\subsubsection{Workload and intention}

The relationship between workload and intention to use the website appeared to be rather ambivalent. Almost half of the sample $(n=9)$ perceived high work pressure during working hours as an impediment to consulting the website. In contrast, three respondents suggested that the website might lower work pressure for infection control professionals, as they will receive fewer questions from HCWs. Additionally, website use seemed to be easily compatible with daily work practice, as 17 respondents mentioned that HCWs have become experienced with technology. This mixed effect of technology on HCWs has been identified in previous research. A study entitled "What Do Nurses Have to Say About Information Technology in Their Workplace?" demonstrated that nurses perceive an added value to technology, but at the same time "often feel exhausted and stressed out after dealing with technology in the workplace" [34]. Technology can create more work for HCWs, as it requires more knowledge and a precise understanding of the technology, which implies that HCWs must learn to use the technology.

\subsubsection{Interpersonal communication}

Another factor that can influence website adoption, both in a positive and negative sense, is interpersonal communication. The majority $(n=11)$ of respondents agreed that consulting a colleague would be more efficient than searching for guidelines on the Internet. Conversely, a personal recommendation of the website among HCWs was considered the second most effective facilitator of website adoption $(n=12)$. Interpersonal communication has been mentioned previously as the most effective communication channel for realizing change or stimulating adoption of new technology [35]. Interpersonal communication provides an opportunity to tailor information to recipients [36]. Other suggestions were that the website could best be promoted during obligatory training sessions $(n=13)$ held by the infection control nurse, who was considered the most important opinion leader by half of the sample. These facilitators are all related to the category of organizational factors in the conceptual framework. Obviously, the organization contains features or elements that enable HCWs to more readily adopt a new technology. As most of the interview statements (131 out of 361) were related to this organizational category, and the majority of these statements were positive $(n=90)$, the organization appeared to be a paramount source of support and reinforcement for sustaining technology adoption by individual HCWs. This finding is in line with the assumptions of the PRECEDE model that we used as a framework for guiding our study, and which has also been demonstrated in previous studies $[15,37,38]$. However, quali- tative research does not enable us to draw conclusions about causal relationships or the strength of relationships between categories of factors in the framework, or about intentions to use the website. In this regard, structural equation modeling could be of major value.

\subsubsection{Value of the PRECEDE model}

The PRECEDE model appeared appropriate to study factors affecting HCWs' adoption of a website with infection control guidelines. The PRECEDE model, which normally is used in health education, enabled us to study website adoption from a multi-faceted view. In contrast to other models such as UTAUT and Social-Cognitive Theory, PRECEDE acknowledges that a successful adoption-enhancing intervention should consider factors from multiple categories that are intertwined, starting with the organization [38]. Our findings, seen from a PRECEDEpoint-of-view, stratify the areas that will speed up the rate of adoption according to Rogers [39]:

- Reinforcing factors: When HCWs witness that opinion leaders and peers have adopted the website (subjective norm), it improves the prospect that the individual HCW will copy the behavior (observability). Next, when infection control nurses incorporate website use in their training sessions and let HCWs work with the website during training (training/feedback), HCWs can try out the innovation without total commitment and with minimal investment, which improves adoption rates (trialability).

- Enabling factors: If HCWs have become skilled in using technology during work practice (work experience), and sufficient computers are available on the ward (infrastructure), the ability of an innovation to coexist with technologies and social patterns already in place will increase, which improves the prospects for adoption (compatibility).

- Predisposing factors: When the individual HCW perceives no difficulties in using the website in practice (complexity), and anticipates to benefit from using the website (relative advantage), he/she is more likely to adopt the website.

\subsubsection{User-centered design}

Overall, our findings highlight the need for general efforts to systematically include end users of technologies in the design and production process of technologies [23]. We could not have foreseen the determinants respondents came up with, nor the fact that determinants would differ so much between various target groups: Whereas infection control staff (in particular) suggested more abstract, strategic factors, nursing staff raised more practical ideas to stimulate adoption. Taking into account these target groups' perceptions can contribute to the eventual success of the technology [23]. Engagement of those responsible for adoption is considered indispensable by Greenhalgh et al. [40]. These authors claim that people are not passive recipients of innovations. Rather, they seek innovations, experiment with them, evaluate them, find meaning in them, develop feelings about them, challenge them, worry about them, complain about them, "work around" them, gain experience with them, modify them to fit particular tasks, and try to improve or redesign them-often through dialogue with other users. 
Table 6 - Intervention directions to enhance the adoption of web-based guideline communication, as suggested by interview respondents $(n=20)$.

Intervention directions

Website itself

- Inform about the frequency with which guidelines are updated

- Emphasize that the guidelines provided by the website are in concurrence with

the best available evidence by providing hyperlinks to original sources

- Explicitly clarify who created the website

Implementation of the website

- Make infection control professionals aware of their role as opinion leaders, and

the importance of them advocating website use

- Emphasize that promoting website use among health care workers can decrease

the workload of infection control professionals (as they will receive fewer

questions when heath care workers retrieve the answers from the website)

- Promote the website during obligatory training sessions for all occupational

groups

- Enable health care workers to work with the website during these obligatory

training sessions

- Encourage personal recommendations of the website among co-workers

Website design team

- Promote website use among health care workers by providing leaflets, sending

e-mails, and stimulating infection control nurse to include a link to the website in

locally enforced guidelines

\subsection{Practical implications}

\subsubsection{Multi-faceted intervention}

The aforementioned facilitators of technology adoption should be combined in an intervention. Multi-faceted intervention strategies have more chance of success than do single-faceted approaches or promotion programs focusing on one or two elements only. When various intervention strategies are used in combination, starting with organizational factors, they are probably more effective than interventions affecting individuals only (to the extent that they influence social norms) [41]. Our study provides specific directions for such a multi-faceted intervention (see Table 6).

\subsubsection{Enhance website's credibility}

First, it is important for the website design team to ensure that the website meets all HCWs' needs, which in case of a website with clinical guidelines, involves guaranteed credibility. Table 6 summarizes the suggestions put forward by the HCWs in our sample. Another way to improve credibility is by applying for certification. The Health on the Net Foundation (HON), for instance, developed an accreditation system to improve the quality of medical and health information online [42]. Several other initiatives have been undertaken to develop such quality markers, although their success has not yet been clearly determined [43].

\subsection{Opinion leaders and workload reduction}

Second, medical and infection control professionals with resistance to new technologies should be predisposed favorably by emphasizing their roles as opinion leaders. For this purpose, they could be personally approached by the website design team. In order to trigger infection control professionals to advocate website use among HCWs, the website design team should stress in a personal conversation that website use by HCWs can reduce work pressure for infection control staff (as HCWs will use the website to look up guidelines instead of seeking advice from the infection control nurse time after time). For this type of conversation between the design team and the infection control staff, persuasive interview techniques can be used. Persuasive interviewing incorporates communication dynamics to influence the behavior of the respondent [44].

\subsubsection{Training sessions}

Third, when infection control staff are willing to promote website use, this should optimally be performed during obligatory training sessions. Allowing HCWs to work with the website for several minutes during this training will trigger them to use it in their daily work practice. The infection control nurse should also dispel HCWs' fear that work pressure is too high to consult the website during work hours. They can mention that, at first, it will take some time to familiarize oneself with the website, but that website use will yield time in the future when they would no longer have to consult a colleague or the infection control staff, and therefore it is worth the investment in learning to work with the website.

\subsubsection{Interpersonal communication}

Fourth, as interpersonal communication appeared to be the dominant way of stimulating website use among HCWs, it is important to ensure that HCWs mutually recommend the website. The website team can encourage this by reminding HCWs of the website's existence by supplying leaflets, e-mails, etc. However, in order to achieve successful implementation (in the sense that HCWs incorporate the website into their daily work routine), more is needed: Interpersonal processes are most successful if they are collaborative, and therefore it is of vital importance to stimulate awareness that infection control is a collective management problem requiring the active involvement of infection control, medical, and nursing staff. 
By focusing on interpersonal exchange, network approaches can potentially facilitate the "predisposing, enabling, and reinforcing" required for the consistent and long-term adoption of best practices [13].

The most effective way to change infection control professionals' perception is by promoting personal interaction between nursing and infection control staff. Direct interaction permits the sharing of tacit knowledge, which is the practical and experiential wisdom HCWs have without being aware of it and that appeared to be a major barrier among HCWs to use the website. Ongoing interaction between peers might create a form of sense-making within the organization about the importance of guideline adherence and the website's benefits [45]. When HCWs discuss the risks, health benefits, and dangers of nosocomial infections, all individuals (including physicians and infection control professionals) become more aware of the fact that he or she will be held responsible for their clinical practice [4]. In this way, direct interaction facilitates individual feelings of accountability, and consequently, rules and guidelines become effective mechanisms for social control (which will also facilitate website adoption). Such an approach is also called "knowledge sharing," which can be seen as a dual process of enquiring and contributing to knowledge through activities such as learningby-observation, listening and asking, sharing ideas, giving advice, recognizing cues, and adopting patterns of behavior [45]. An intervention based on this approach significantly reduced the MRSA rate in England. This approach differs from other types of interventions because of its involvement of all staff in its development and application. In addition, information exchange, employee participation, and social networking are emphasized during the intervention process [46].

\subsection{Limitations}

The findings of this study are limited by the fact that the respondents were all familiar with the website and therefore were more favorably predisposed toward website use compared to those who not know the website. Future research should involve both users and non-users. A second limitation of this study is the small sample size, which limits the ability to generalize the findings.

Although qualitative methods enabled us to optimally explore HCWs' perspective toward factors affecting website adoption, we could have benefited from quantitative techniques. Validated instruments such as UTAUT are available to measure determinants of technology adoption [14]. However, it appeared that the scales for the UTAUT constructs are not robust and stable across settings and therefore are likely to effect the interpretation of results [47].

Furthermore, we did not measure the effectiveness of the interventions strategies proposed in Table 6. Overall, the evidence on impacts of adoption-enhancing interventions is weak. Testing of intervention directions generated by this study in prospective trials may help establish evidence for such impacts [13]. This remains a subject for future research.

\section{Summary points}

What was known before the study?

- Health care workers' (HCWs) adherence to electronic, web-based guidelines is higher than their adherence to paper-based guidelines, when tested in clinical scenarios.

- Despite the proven value of web-based guidelines, there are still numerous obstacles to the adoption of web-based guidelines in daily work practice. Previous studies expressed the need for research on factors affecting adoption that are specific to the technology under consideration.

- Previous studies of HCWs' perceptions of web-based guideline communication have not been based on established theories.

What has the study added to the body of knowledge?

- A user-centered design process and validated principles for web design and usability do not guarantee that potential adopters will be favorably predisposed toward the technology. The website's credibility, as perceived by the adopters, is an important additional requirement.

- The relationship between workload and technology adoption is ambivalent. On the one hand, HCWs' high workloads hinder them from using technology during working hours. On the other hand, the same technology can help decrease workload. This ambivalence calls for further investigation.

- The organization is a paramount source of support and reinforcement for sustaining technology adoption by individual HCWs. Interventions aimed at technology adoption should therefore start with organizational factors, e.g., by encouraging use of the technology during training courses.

- Involvement of potential adopters in the adoption process creates a sense of community around technology. This creates a sense of ownership, fosters applicability of the website, and leads to a willingness to integrate the website into daily practice.

\section{Conclusion}

Factors at multiple levels determine HCWs' adoption of webbased guidelines, but training and feedback appear to be a paramount reinforcer of initiation and maintenance of technology adoption. Since HCWs may prefer personal experience and communication with colleagues over online sources, it is of vital importance to construct a website that addresses HCWs' particular needs and ensures that the technology fits within the informal mechanisms of communication operative in HCWs' social networks. This can be realized through the involvement of potential adopters in the development and implementation process. 


\section{Acknowledgements}

This study was financially supported through the EUREGIOMRSA-net Twente/Münsterland under the European Regional Development Fund (ERDF), which is funded by the European Union within the Community Initiative INTERREG-IIIA (2-EUR-V-1 =96), as well as by the Ministry of Economics in the German state of Nordrhein-Westfalen. Furthermore, we thank the respondents for their contributions and Ansfrida Vreeburg for conducting and transcribing the interviews.

Authors' contributions: FV and JEWCvG designed the study and analyzed the results. RMGH provided microbiological expertise, validated the scenarios, and helped with interpreting the results. MFS edited the final version of the manuscript. All authors contributed to the writing of the paper and have approved this final version.

\section{REFERENCES}

[1] D. Pittet, L. Donaldson, Challenging the world: patient safety and health care-associated infection, Int. J. Qual. Health Care 18 (1) (2006) 4-8.

[2] M. Berhe, M.B. Edmond, G.M. Mearman, Practices and an assessment of health care workers' perceptions of compliance with infection control knowledge of nosocomial infections, Am. J. Infect. Control 33 (1) (2005) 55-57.

[3] J.E.W.C. van Gemert-Pijnen, M.G.R. Hendrix, J. van der Palen, P.J. Schellens, Performance of methicillin-resistant Staphylococcus aureus protocols in Dutch hospitals, Am. J. Infect. Control 33 (7) (2005) 377-384.

[4] B. Fervers, J.S. Burgers, M.C. Haugh, M. Brouwers, G. Browman, F. Cluzeau, T. Philip, Predictors of high quality clinical practice guidelines: examples in oncology, Int. J. Qual. Health Care 17 (2) (2005) 123-132.

[5] J. Jeannot, F. Scherer, V. Pittet, B. Burnand, J. Vader, Use of the World Wide Web to Implement Clinical Practice Guidelines: a feasibility study, J. Med. Internet Res. 5 (2) (2003) e12.

[6] L. Casebeer, N. Bennett, R. Kristofco, A. Carillo, R. Centor, Physician Internet medical information seeking and online continuing education use patterns, J. Contin. Educ. Health Prof. 22 (1) (2002) 33-42.

[7] K.W. Thomas, C.S. Dayton, M.W. Peterson, Evaluation of Internet-based clinical decision support systems, J. Med. Internet Res. 1 (2) (1999) e6.

[8] A.H. Morris, Developing and implementing computerized guidelines for standardization of clinical decisions, Ann. Int. Med. 132 (5) (2000) 373-383.

[9] J.M. Grimshaw, I.T. Russell, Effect of clinical guidelines on medical practice: a systematic review of rigorous evaluations, Lancet 8883 (342) (1993) 1317-1322.

[10] A.X. Garg, N.K. Adhikari, H. McDonald, M.P. Rosas-Arellano, P.J. Deveraux, J. Beyene, J. Sam, R.B. Haynes, Effects of computerized clinical decision support systems on practitioner performance and patient outcomes: a systematic review, JAMA 293 (10) (2005) 1223-1238.

[11] M. Cain, R. Mittman, Diffusion of Innovation in Health Care, California Health Care Foundation, Oakland, 2002.

[12] N. Rousseau, E. McColl, J. Newton, J. Grimshaw, M. Eccles, Practice based, longitudinal, qualitative interview study of computerized evidence based guidelines in primary care, BMJ 326 (7384) (2003) 314.
[13] R. Grol, M. Wensing, What drives change? Barriers to and incentives for achieving evidence-based practice, Med. J. Aust. 15 (180) (2004) S57-S60.

[14] O. Peters, Social Psychological Determinants of Mobile Communication Technology Use and Adoption. A Comparison of Three Models to Explain and Predict Mobile Communication Technology Behavior, University of Twente, Enschede, 2007.

[15] D.M. DeJoy, C. Searcy, L.R. Murphy, R.M. Gershon, Behavioral-diagnostic analysis of compliance with universal precautions among nurses, J. Occup. Health Psychol. 5 (1) (2000) 127-141.

[16] R.R.M. Gershon, D. Vlahov, S.A. Felknor, D. Vesley, P.C. Johnson, G.L. Delclos, L.R. Murphy, Compliance with universal precautions among health care workers at three regional hospitals, Am. J. Infect. Control 23 (4) (1995) 225236.

[17] P.M. McGovern, D. Vesley, L. Kochevar, R.R.M. Gershon, F.S. Rhame, E. Anderson, Factors affecting universal precautions compliance, J. Bus. Psychol. 15 (1) (2000) 149-161.

[18] T. Lundstrom, G. Pugliese, J. Bartley, J. Cox, C. Guither, Organizational and environmental factors that affect worker health and safety and patient outcomes, Am. J. Infect. Control 30 (2) (2002) 93-106.

[19] A.L. Francke, M.C. Smit, A.J.E. de Veer, P. Mistiaen, Factors influencing the implementation of clinical guidelines for health care professionals: a meta-review, BMC Med. Inform. Decis. Mak. 38 (8.) (2008).

[20] G. Eysenbach, J. Powell, O. Kuss, S. Eun-Ryoung, Empirical studies assessing the quality of health information for consumers on the World Wide Web. A systematic review, JAMA 287 (20) (2002) 2691-2700.

[21] C. Kerr, E. Murray, F. Stevenson, C. Gore, I.I. Nazareth, Internet interventions for long-term conditions: patient and caregiver quality criteria, J. Med. Internet Res. 8 (3) (2006) e13.

[22] A.W. Friedrich, I. Daniels-Haardt, R. Köck, F. Verhoeven, A. Mellmann, D. Harmsen, J.E.W.C. vanGemert-Pijnen, K. Becker, M.G.R. Hendrix, EUREGIO MRSA-net Twente/Münsterland-A Dutch-German cross-border network for the prevention and control of infections caused by Methicillin-resistant Staphylococcus aureus, Eurosurveillance 35 (13) (2008) 1-11.

[23] M. Kinzie, W. Cohn, M. Julian, W.A. Knaus, A user-centered model of website design: needs assessment, user interface design and rapid prototyping, J. Am. Med. Inform. Assoc. 9 (4) (2002) 320-330.

[24] Dutch Workingparty on Infection Prevention, MRSA, Hospitals, Dutch Working Party on Infection Prevention, Leiden, 2005.

[25] The Committee for Hospital Hygiene and Infection Prevention at the Robert Koch Institute, Empfehlung zur Prävention und Kontrolle von Methicillin-resistenten Staphylococcus aureus (MRSA) in Krankenhäusern und anderen medizinischen Einrichtungen [Recommendation] for Prevention and control of Methicillin-resistant Staphylococcus aureus (MRSA) in hospitals, Bundesgesundheitsbl Gesundheitsforsch Gesundheitsschutz 42 (12) (2002) 954-958.

[26] F. Verhoeven, J.E.W.C. van Gemert-Pijnen, A.W. Friedrich, I. Daniels-Haardt, M.G.R. Hendrix, M.F. Steehouder, The development of a web-based information tool for cross-border prevention and control of Methicillin Resistant Staphylococcus aureus, Int. J. Inf. Control 4 (1) (2008) 1-11.

[27] M. McRobb, Writing Quality Manuals for ISO 9000 Series, IFS Publications, London, 1990.

[28] S.J. Koyani, R.W. Bailey, J.R. Nall, Research-Based Web Design \& Usability Guidelines, U.S. Government Printing Office, Washington, DC, 2006. 
[29] L. van Velsen, T. van der Geest, R. Klaassen, M. Steehouder, User-centered evaluation of adaptive and adaptable systems: a literature review, Know. Eng. Rev. 23 (3) (2008) 261-281.

[30] M.W. Patton, Qualitative Evaluation and Research Methods, Sage Publications, Newbury Park, 1990.

[31] J.R. Landis, G.G. Koch, The measurement of observer agreement for categorical data, Biometrics 33 (1) (1977) 159-174.

[32] R. McDonald, J. Waring, S. Harrison, K. Walshe, R. Boaden, Rules and guidelines in clinical practice: a qualitative study in operating theatres of doctors' and nurses' views, Qual. Saf. Health Care 14 (4) (2005) 290-294.

[33] D. Parker, R. Lawton, Judging the use of clinical protocols by fellow professionals, Soc. Sci. Med. 51 (5) (2000) 669-677.

[34] M.Y. Ho, E.J.S. Hovenga, What Do Nurses Have to Say About Information Technology in Their Workplace? HIC 99: Proceedings, Health Informatics Society of Australia, Brunswick East, 1999.

[35] L.A. Bero, R. Grilli, J. Grimshaw, E. Harvey, A.D. Oxman, M.A. Thomson, Closing the gap between research and practice: an overview of systematic reviews of interventions to promote the implementation of research findings, BMJ 317 (7156) (1998) 465-468.

[36] I. Williams, H.H. Dickinson, Knowledge for Adoption: A Review of the Literature on Knowledge-based Facilitators of Technology Adoption in Health Care, HSMC/NHSI, University of Birmingham, Birmingham, 2008.

[37] B. Kaplan, Addressing organizational issues into the evaluation of medical systems, J. Am. Med. Inform. Assoc. 4 (2) (1997) 94-101.
[38] R. Kukafka, J.B. Johnson, A. Linfante, J.P. Allegrante, Grounding a new information technology implementation framework in behavioral science: a systematic analysis of the literature on IT use, J. Biomed. Inform. 36 (3) (2003) 218-227.

[39] E.M. Rogers, Diffusion of Innovations, Free Press, New York, 2003.

[40] T. Greenhalgh, G. Robert, F. Macfarlane, P. Bate, O. Kyriakidou, Diffusion of innovations in service organizations: systematic review and recommendations, Milbank Quarterly 82 (4) (2004) 581-629.

[41] D. Pittet, Infection control and quality health care in the new millennium, Am. J. Infect. Control 33 (5) (2000) 258-267.

[42] HON code on conduct (HONCode) for medical and heath web sites, www.hon.ch/HONcode/ (accessed February 3rd 2009).

[43] H. Rippen, A. Risk, E-Health code of ethics, J. Med. Internet Res. 2 (2) (2000) e9.

[44] D. Rabon, T. Chapman, Persuasive Interviewing, Carolina Academic Press, Durham, 1994.

[45] R. Bosua, R. Scheepers, Towards a model to explain knowledge sharing in complex organizational environments, Know. Mngt. Res. Pract. 5 (2) (2007) 93-109.

[46] D. Cooper, K. Farmery, M. Johnson, C. Harper, F.L. Clarke, P. Holton, S. Wilson, P. Rayson, H. Bence, Changing personnel behavior to promote quality care practices in an intensive care unit, Ther. Clin. Risk Manag. 1 (4) (2005) 321-332.

[47] J.P. Li, R. Kishore, How robust is the UTAUT instrument?: a multigroup invariance analysis in the context of acceptance and use of online community weblog systems, in: ACM SIGMIS CPR: Proceedings, Claremont, 2006. 